\title{
Child and adolescent psychiatry as a clinical neuroscience
}

\author{
A tribute and farewell to Andreas Warnke
}

\author{
Beate Herpertz-Dahlmann
}

Received: 15 March 2010/Accepted: 15 March 2010/Published online: 3 April 2010

(C) Springer-Verlag 2010

When Andreas Warnke was invited in 2001 by Peter Riederer to become the first field editor of "Biological Child and Adolescent Psychiatry" in this journal, our discipline had only just begun to define itself as a clinical neuroscience. However, Peter Riederer made an excellent choice. Andreas Warnke was one of the first German chair holders of Child and Adolescent Psychiatry who pursued biological research in human mental processes. Together with his mentor Helmut Remschmidt he had understood that the basic sciences of psychiatry had to include genetics, neuroimaging, neurochemistry, and neurophysiology. He also realized that research of the developing brain would be a unique source for a better understanding of cause and pathophysiology of mental disorders in general. Consequently, he is one of the editors of the first German handbook on "Developmental Psychiatry". In 1993, he inaugurated the "National Conference of Biological Child and Adolescent Psychiatry" in Würzburg, which nowadays takes place every year at a different site. For the last time Andreas Warnke was the president of this conference in December 2009. For his merits in "Biological Child and Adolescent Psychiatry" he was awarded the "Heinrich Hoffmann-Medal", which is the highest scientific and political reward of the German Scientific Society for Child and Adolescent Psychiatry, Psychosomatics and Psychotherapy.

Biological developmental child and adolescent psychiatry is engaged in exploring vulnerability genes in complex mental disorders like autism and schizophrenia. With the

B. Herpertz-Dahlmann $(\bowtie)$

Klinik für Kinder- und Jugendpsychiatrie und -psychotherapie, Universitätsklinikum Aachen, Neuenhofer Weg 21,

52074 Aachen, Germany

e-mail: bherpertz-dahlmann@ukaachen.de help of Andreas Warnke, this journal has been an important platform to publish major findings in child and adolescent psychiatric genetics.

However, the development of mental processes is far more than the expression of a genetic liability. The preeminent question is how the brain gives rise to various mental processes (Kandel 1998). In human beings genetic disposition interacts with social environment. A certain psychosocial experience may have lasting effects on behavior by changes of gene expression, a process which is called epigenetic. Special proteins may help to identify such processes in the brain-the field of proteo- and metabolomics. A. Warnke was the first to support this kind of research in German child and adolescent psychiatry, which in future might lead to early detection and probably prevention of major mental disorders (Insel and Quirion 2005). His co-workers in Wurzburg further engage in neuroimaging and neurophysiology, which are major research areas represented in this journal. However, Andreas Warnke never denied the importance of interpersonal relationship in the etiology, but also the treatment of psychiatric diseases in childhood. He was always absolutely convinced that evidence-based psychotherapeutic approaches would be a major resource for a good outcome in child and adolescent mental illness. Probably, it is only a matter of time till we understand the biological processes in the brain underlying a successful psychotherapy.

The main research interests of $\mathrm{A}$. Warnke were dyslexia, where he is integrated in several European research projects and attention deficit/hyperactivity disorder (ADHD). To foster research in ADHD, he organized two international congresses together with Manfred Gerlach in Würzburg and Vienna. He is the principal investigator of a huge project of the German Ministry of Education and Research to investigate the effect of mother's ADHD on 
the child's treatment response. The latter project uniquely characterizes his way of thinking: besides genetic research and classification of the phenotype of ADHD and its co-morbidities, the relationship between mother and child is the main focus of his research. Thus, A. Warnke has satisfied both: the biologist of the brain and the psychiatrist of the mind.

Being the first field editor of our discipline in this journal, Andreas Warnke has provided German Child and Adolescent Psychiatry with a very important forum to publish our neuroscientific findings. Last year it was realized that most English language articles of German researchers in child and adolescent psychiatry were published in the Journal of Neural Transmission (Hebebrand et al. 2009).

I would like to thank Peter Riederer who so gently accepted child and adolescent psychiatry as a member of the scientific community contributing to this journal.

Last but not least, I want to thank Andreas Warnke for his enthusiasm, his wonderful ideas, his efforts in training young clinical doctors to also become successful neuroscientists and for the way he was able to acknowledge the contribution of others-in short, for his outstanding engagement for our discipline to become an equal member of the society of clinical neurosciences.

It is a gift to be his colleague and friend and a great honor to succeed him as field editor for "Biological Child and Adolescent Psychiatry" in the Journal of Neural Transmission.

\section{References}

Hebebrand J et al (2009) Research report of the German child and adolescent psychiatry. Z Kinder Jugendpsychiatr Psychother 37:231-233

Insel TR, Quirion R (2005) Psychiatry as a clinical neuroscience discipline. JAMA 294:2221-2224

Kandel ER (1998) A new intellectual framework for psychiatry. Am J Psychiatry 155:457-469 